\title{
Gestão em Ciência, Tecnologia e Inovação no contexto da informa- ção: na trilha dos estudos de avaliação
}

A gestão de produtos, recursos, serviços e processos é fundamental para a definição de políticas, estratégias e planos de ação, nas diversas esferas institucionais, especialmente, nos domínios da Ciência, Tecnologia e inovação (CT\&I). Como uma das etapas do planejamento estratégico, a avaliação é importante atividade gerencial, na medida em que condiciona a análise, o monitoramento e a prospecção de desempenhos de pessoas, instituições e organizações, entre outras.

Nesse contexto, trata-se de um importante instrumento de gestão que tem como finalidade a determinação sistemática de mérito, estipulação de valor e importância de algo, usando critérios, objetivos ou subjetivos, orientados por um conjunto de padrões. $O$ ato de avaliar, nessa perspectiva, implica dois processos articulados e indissociáveis: diagnosticar e decidir. Não é possível uma decisão acertada sem um diagnóstico, e um diagnóstico, sem uma decisão é um processo abortado (LUCKESI, 2000) ${ }^{1}$.

Com efeito, a avaliação faz parte de um conjunto de atividades que busca, em última análise, a eficiência e a eficácia em organizações complexas, tomando como referência os ajustes necessários entre as diversas atividades nelas realizadas, sem perder de vista os diferentes contextos sociais, políticos, econômicos e culturais.

É, pois, fundamental considerar que a avaliação não é uma prática neutra porque é realizada em contextos social e historicamente determinados, a partir de condições concretas, dentro de um quadro de referências que confere justificativa e coerência, ou seja, quando se opta por um determinado modelo de avaliação este se relaciona a "[...] certas opções epistemológicas, éticas e políticas, as quais correspondem a uma certa visão de mundo, conforme objetivos e resultados pretendidos." (SUASSUNA, 2007, p. 38) ${ }^{2}$.

Ao situarmos a avaliação no campo das modalidades de intervenção social e, especificamente, nas ciências sociais, podemos considerá-la como a aplicação de "[...] procedimentos que, apoiados no uso do método científico, servem para identificar, obter e proporcionar a informação pertinente e julgar o mérito e o valor de algo de maneira justificável." (AGUILAR; ANDER-EGG, 1994, p. 23) ${ }^{3}$.

Assim, podemos considerar que a avaliação envolve diferentes atividades como, por exemplo, observar, documentar e medir. Esse processo é conduzido comparando o desempenho alcançado tendo em vista o planejamento, a execução, os resultados alcançados.

No campo da Ciência da Informação, trabalhos sobre componentes conceituais e metodológicos de avaliação, principalmente de indicadores, qualitativos e quantitativos, não são recentes e demonstram uma variedade de contextos de aplicação (SWANSON; MAYER, 1975), em processos, produtos, recursos e serviços de informação.

\footnotetext{
${ }^{1}$ LUCKESI, C. C. O que é mesmo o ato de avaliar a aprendizagem? Revista Pátio, ano 4, n. 12, p. 6-11, fev. 2000.

2 SUASSUNA, L. Paradigmas de avaliação: uma visão panorâmica. In: MARCURSCHI, B.; SUASSUNA. L. (Org.) Avaliação em língua portuguesa: contribuições para a prática pedagógica. Belo Horizonte: Autêntica, 2007. p. 27-44.

${ }^{3}$ AGUILAR, M. J.; ANDER-EGG, E. Avaliação de Serviços e Programas Sociais. Petrópolis: Editora Vozes, 1994.
} 
O presente número da Ciência da Informação traz um conjunto de oito relatos de pesquisa que se dedicam a esse domínio de estudo. No primeiro deles, "Ciência da Informação e História: os estudos históricos nos programas de pós-graduação brasileiros da área de Ciência da Informação", os autores Leonardo Gonçalves Silva e Lúcia Maciel Barbosa de Oliveira buscaram na literatura as relações entre Ciência da Informação e História, com o intuito de verificar se os pesquisadores brasileiros da área da Ciência da Informação com formação em História realizam pesquisas históricas sobre o tema da informação. Os resultados do estudo apontam que, mesmo havendo uma quantidade razoável de docentes com formação em História atuando nos programas de pós-graduação da área, são poucos os que realizam pesquisas históricas em contextos informacionais. Segundo os autores, as pesquisas históricas dentro da Ciência da Informação ainda são poucas e necessitam ser ampliadas tendo em vista que podem enriquecer a área e trazer novos temas de discussão e uma compreensão adensada da informação em diferentes contextos.

Em "Estudo bibliométrico da produção científica dos docentes do Departamento de Física da UFMG entre 2012 e 2016", os autores Carlos Basílio Pinheiro, Gabriela Silva Caetano e Bruno Fernandes Magalhães de Oliveira investigam na base de dados Scopus e nas plataformas Somos UFMG, Lattes e SCImago Journal \& Country Rank (SJR) a produção científica do Departamento de Física do Instituto de Ciências Exatas da Universidade Federal de Minas Gerais (ICEx/UFMG). Segundo os autores, as análises empreendidas sugeriram, dentre outros aspectos, uma queda consistente da produção nos anos investigados; com concentração da produção em grupo pequeno de docentes; positiva correlação entre idade/tempo de doutorado e produtividade; e correlação inversa entre produtividade e número total de citações, bem como de tempo de permanência na UFMG.

No relato de pesquisa "Produção e disseminação de conhecimento: as temáticas abordadas em 19 anos da Revista Brasileira de Estudos Urbanos e Regionais (RBEUR)", os autores Rubens Staloch e Isa de Oliveira Rocha analisam de forma quantitativa e descritiva as temáticas abordadas nos artigos publicados na RBEUR, desde sua primeira edição. Os autores constataram, dentre outros achados, que a temática "planejamento e gestão urbana e/ou regional" é que mais se destaca entre o total de 322 artigos publicados nos 19 anos de existência da Revista.

No relato de pesquisa "Relações de poder entre gêneros no ambiente organizacional: uma análise da representação feminina nas empresas de Tecnologia da Informação (TI) de Porto Alegre - RS", os autores Francielle Piffero Camargo, Cláudia Lehnemann Tannhauser, Uiliam Hahn Biegelmeyer, Maria Emilia Camargo, Flávia Camargo Bernardi e Tânia Craco analisaram os motivos que impedem o ingresso e a permanência das mulheres na área de $\mathrm{TI}$, bem como a inserção atual, a atuação e as relações de poder que caracterizam este mercado. Por meio de uma pesquisa qualitativa exploratória, os autores entrevistaram 10 mulheres que trabalham na área de $\mathrm{TI}$ e os resultados apontaram para a existência de diferenças de gênero significativas na área, tanto no ambiente acadêmico, que leva à desistência de parte das mulheres, quanto no ambiente organizacional e nas práticas e relações do dia a dia, que as colocam em uma situação subalterna e discriminatória.

No relato de pesquisa "Mediação informativo-cultural: e a formação dos mediadores?", a autora Marielle Barros de Moraes analisa como a temática da mediação da informação e da cultura está inserida nos currículos dos cursos das ciências da informação na Iberoamérica, por meio da análise de conteúdo, bem como da análise comparativa de currículos de duas universidades cujos cursos da área estão vinculados à Asociación de Educación e Investigación en Ciencia de la Información de Iberoamérica y el Caribe (EDICIC). A autora 
demonstra que, nos textos dos projetos pedagógicos dos cursos do Brasil e da Colômbia analisados, embora com algumas diferenças locais, a mediação é abordada de forma indireta, como algo que perpassa toda a atividade dos profissionais da informação, mas não é abordada, especificamente, como campo de reflexão próprio.

No relato de pesquisa "Análise documental na Museologia: um breve exercício de identificação de conceitos", os autores Mateus da Silva Reis, João Batista Ernesto de Morais, Thiago Henrique Bragato Barros e Roberto Lopes dos Santos Junior discutem as etapas de cunho analítico e sintético da Análise Documental, indicando seus objetivos em relação ao tratamento documental em museus, além de noções sobre documentação museológica. $\mathrm{O}$ estudo utilizou como base textos e artigos ligados à Museologia que abordam, direta ou indiretamente, o tema, a partir de registro e organização das informações (leituras documentárias, descrição, classificação) dos acervos museológicos. Os autores identificaram que a temática ligada à relação entre Análise Documental e documentação museológica apresenta um promissor campo de estudo, identificando a importância da continuação de pesquisas que lidam sobre o tema, permitindo maior aprimoramento teórico e prático dos museólogos em relação à organização e representação da informação.

No relato de pesquisa "A inteligência analítica em pequenas unidades do Setor de Segurança Pública no Sul de Minas Gerais", os autores Djair Picchiai e Alan Rocha fazem um levantamento sobre a inteligência analítica (IA), na percepção dos gestores dos Destacamentos da Política Militar (PM), que tem um papel fundamental para auxiliar na busca por meIhores resultados, bem como no planejamento operacional. Por meio da aplicação de um questionário, os autores constataram que os gestores de pequenas unidades da PM de Belo Horizonte, demostraram ter convicção da importância dos Destacamentos, baseando-se na afirmativa de que o serviço de inteligência é relevante do ponto de vista da operacionalidade.

Por fim, no relato de pesquisa, "Gestão por processos em organizações públicas: mapeamento dos processos administrativos do Departamento de Registro e Controle Acadêmico da UFAL", as autoras Anna Cynthia Barros de Albuquerque e Luciana Peixoto Santa Rita analisaram os processos e as rotinas do Departamento de Registro e Controle Acadêmico da Universidade Federal de Alagoas (DRCA/UFAL), segundo os preceitos da gestão por processos. Para tanto, adotaram a abordagem qualitativa com consulta a diversas fontes de evidências como, por exemplo, documentação, registros em arquivos, entrevistas estruturadas e observação direta e participante. As autoras identificaram e mapearam 44 (quarenta e quatro) processos. Como resultado, propuseram um manual para o DRCA/UFAL com os devidos ajustes nos processos e rotinas.

A Ciência da Informação em Revista agradece aos autores pela produção dos artigos e aos avaliadores pela análise e emissão dos respectivos pareceres. Deseja, enfim a todos, uma boa leitura.

\section{Edivanio Duarte de Souza}

Ronaldo Ferreira de Araújo

Editores 